\title{
COMPARTIENDO MIRADAS O LA POESÍA DE LO ORDINARIO. EXPERIENCIAS DEL CINE
}

\author{
Alicia C. Naput (Universidad Nacional de Entre Ríos)* \\ anaput@gmail.com
}

Recibido: 29/07/2011 Aceptado: 26/10/2011

Este espacio de visionado compartido y conversación en torno a los films, se sustenta en dos inquietudes educativas. A saber: La autorización a tomar la palabra, el darse ese derecho, tomado de sí mismo; y, de otro lado, la pregunta y el interés por la performatividad del cine (Cavell, S: 2008). En otros términos, el tránsito hacia una sensibilidad libre, la educación de la experiencia a través del cine.

Así, desde el año 2008 hemos abierto este ciclo, primero desde las cátedras de Política de la Educación y Teoría Política (de Ciencias de la Educación y Comunicación Social, respectivamente) y luego desde la Coordinación de la carrera de Educación de Facultad de Ciencias de la Educación de la UNER. En el primer ciclo "Miradas del '68. La revuelta "entre ojos" o filmar para ver" (auspiciado por al embajada de Francia y el Goethe Institut) compartimos producciones de las revueltas juveniles de 1968. En el segundo, "Entre la imaginación del desastre y las figuraciones del porvenir", se hizo foco en los modos como los dispositivos de la sociedad disciplinaria han devenido formas sofisticadas y específicas de control.

Nos interesa la potencia artístico expresiva del cine, más comprometida con la exploración de lo visible que con el interés por lo visual. El valor de tales visibilidades en la constitución de nuestra experiencia -y su potencial como herramienta de autorreflexión crítica- reside, creemos, en su aptitud para ofrecer una visión melodramática de la intimidad de los personajes, sus pensamientos,

* Magister en Educación con mención Filosofía Política. Doctoranda en Educación. Profesora en Ciencias de la Educación. Facultad de Ciencias de la Educación. Universidad Nacional de Entre Ríos. 
sus sentimientos. Visibilidad o, mejor, visibilidades que unas veces exhiben los mecanismos de construcción textual - abriendo un espacio para la interrogación sobre la mirada- y otras se nos imponen casi como mundos propios.

\section{El ciclo: Juventudes y experiencias. Miradas del cine (figuras, actores y realizadores)}

En este espacio en el año 2010 nos propusimos hacer foco en nuestras experiencias en relación con las juventudes. El plural remite a lo múltiple de esa "identidad generacional": la época, las relaciones de clase, de género, étnicas, las tradiciones culturales. La expresión nuestras experiencias, pretende convocar al compromiso de pensar en nosotros (jóvenes y/o adultos) entre otros (jóvenes y/o adultos).

Nos movían algunas certezas. La historicidad de la experiencia, su carácter epocal, contingente e intersubjetivo, su opacidad, su persistente resistencia a la mediación de una lengua única y universal, como su disposición a encarnarse en escrituras y reencarnarse (buscarse) en traducciones (1).

Nos inquietaba la precarización de la vida - no la precariedad constitutiva de lo humano- la pobreza que impone un presente político que expulsa el disfrute y el dolor de la duración de la vida compartida, tanto como la promesa de mundo.

En ese escenario renovábamos la apuesta a mirar juntos y a hacernos tiempo de hablar de nuestra experiencia, esa que es convocada al momento de pensar en las resonancias del film y en la comprensión de su tiempo (Cavell, S: 1999)

Finalmente, sosteníamos que uno necesita tiempo para entender lo que ve, no sólo entender en un nivel intelectual, sino emocional. El cine tiene todavía la capacidad de permitirnos experimentar el mundo de nuevo. Con esa expectativa, esa confianza, compartimos producciones de cineastas consagrados y de jóvenes realizadores.

Organizamos el visionado en dos grandes momentos:

1. Modulaciones de lo real. Juventud, filiación, amor y amistad, en que proyectamos: Rossetta (Bélgica: 1999) y El niño (Bélgica: 2005) de los hermanos Dardenne; Felices juntos (Hong Kong:1997) de Wong Kar Wai.

2. Lugares y tránsitos. Los tiempos de las vidas jóvenes. Producciones de jóvenes realizadores.

En este segundo momento proyectamos dos programas de cortometrajes. Uno, que reunía films de realizadores jóvenes de diversas procedencias y que tematizaban las vidas jóvenes (2); otro, que incluía producciones de estudiantes secundarios de la región, a saber: Paraná y Santa Fe. En esta instancia contamos con la participación activa de los realizadores y sus coordinadores docentes o talleristas (3). 
De la conversación en torno a los films nos interesa subrayar en primer término, el hablar de la experiencia compartida. En los diferentes encuentros emergió en la conversación, en las asociaciones, en la ocurrencia de las identificaciones, esa idea de un experimentar de nuevo el mundo. Es decir la potencia de los films, y la lectura compartida, para poner en foco la propia experiencia del mundo. La propuesta de pensar en el punto de vista narrativo permitió no sólo conversar sobre las juventudes como tema, sino compartir en disidencia cómo las formas narrativas y las visibilidades hablan también de las experiencias de los jóvenes, de sus miradas.

La discusión acerca de la producción de efectos de verosimilitud narrativa, la puesta en escena de la vida, permitió de manera interesante pensar la relación del cine con el mundo y sus efectos performativos más allá del "reflejo" y "el mensaje"; mejor: como referencias múltiples, problemáticas y sujetas a un interpretante ineludible.

Finalmente la instancia del encuentro entre los estudiantes secundarios y sus producciones, en presencia y en diálogo con sus coordinadores, provocó no sólo el entusiasmo en los estudiantes universitarios presentes y también en los propios realizadores, por los films. Reveló de modo más que significativo, la índole de la experiencia educativa del taller de producción audiovisual; el tipo de relación de aprendizaje compartido entre pares y el singular vínculo con los coordinadores. En la conversación se ponía en visibilidad, por un lado, aquello que sobre la transmisión de un lenguaje y una forma de expresión habían aprendido los coordinadores (en la experiencia de producir); y, por otro, aquello que los jóvenes estudiantes habían aprendido acerca de sí mismos, de los diversos modos de aprender, de la relación con los maestros, y del lenguaje audiovisual. Escuchándolos narrar la experiencia, explicar las elecciones temáticas y formales, bromear acerca del trabajo y las sugerencias de sus coordinadores, era posible pensar que no hay UNA escuela. La escuela, en esas experiencias que revisitábamos, en la conversación tras el visionado, era escenario una educación artística. Educación artística que parafraseando a John Casavettes (Jousse, Tierry: 1992) que consiste en el trabajo con otras personas que, en cierto sentido, están todas ligadas entre sí por la tarea que quieren realizar, por aquello que ellos quieren devenir.

De este modo como decíamos al comienzo el papel del cine en la educación de la experiencia, en la toma de la palabra, en el volverse autoridad de sí mismo, adquiría una dimensión en la que no habíamos pensando antes de esta experiencias con los estudiantes secundarios y sus maestros coordinadores; un procesos de subjetivación recíproca del que aun tenemos mucho que aprender. 


\section{Notas bibliográficas}

(1) Porque no renunciamos a la felicidad humana compartida en disidencia, es que tampoco lo hacemos a la pretensión de universalidad, como una tarea de traducción cultural orientada al futuro.

(2) Children loose nothing (Lituania) dir.: Shanuras Bartas; Debajo.(Chile) Dominga Sotomayor; El patio (Argentina) Milagros Numenthaler; Verano (Argentina) Milton Secchi; Esnorquel -(Argentina) Maximiliano Schonfeld; El miracle (Polonia) Martin Sulik; Rey muerto (Argentina) Lucrecia Martel; Acuático (Argentina) Ignacio Lillini; Dizzy (Argentina) Emiliano Pinto; Buen viaje (Uruguay) Guillermo Rocamora y Javier Palleiro; Las insoladas (Argentina)Gustavo Taretto.

(3) Querer no es amar. Ficción, 19': Escuela Nuestra señora de Guadalupe № 28: alumnos de $3^{\circ}$ año polimodal A (Paraná); Animal print y Silencio en la noche: Escuela Juan Mantovani Taller de animación del Trayecto técnico profesional. $4^{\circ}$ año (Santa Fe); Dondever Ficción, Escuela Organización Grupo de Teatro Escuela N382 Barrio Acería (Santa Fe); Gringo. Ficción, Mi música. Documental, DNI. Ficción, 2006, Educación sexual. Ficción y Vos también. Animación: Escuela de Enseñanza Media Nro. 262 "República Argentina (Santa Fe).

\section{Referencias Bibliográficas}

- $\quad$ Cavell, Stanley (1999): La búsqueda de la felicidad, Barcelona, Paidós.

- $\quad$ Cavell, Stanley (2008): El cine, ¿puede hacernos mejores?. Barcelona: Katz.

- Jousse, Tierry (1992): John Cassavettes. Madrid: Ediciones Cátedra. 